\title{
Síntesis y Actividad Biológica de Nuevos Compuestos Gemini Peptídicos
}

\author{
Diana M. Müller ${ }^{(1)}$, María C. Ingaramo(1), María F. Argarañá(2) y Marcelo C. Murguía(3) \\ Facultad de Bioquímica y Cs. Biológicas, Universidad Nacional del Litoral, Ciudad Universitaria - \\ Paraje EI Pozo, C.C. 242- C.P: 3000, Santa Fe-Argentina. \\ (1) Dpto. de Química Orgánica, (e-mail: dianamuller2001@yahoo.com, clara_189@hotmail.com) \\ (2) Cátedra de Microbiología General (e-mail: ferarga@arnet.com.ar) \\ (3) Lab. de Química Aplicada (e-mail: mmurguia@santafe-conicet.gov.ar)
}

Recibido Ene. 04, 2011; Aceptado Feb. 24, 2011; Versión Final recibida Mar. 17, 2011

\section{Resumen}

Se ha sintetizado y evaluado la actividad antimicrobiana de nuevos compuestos gemini derivados de un tetrapéptido. La síntesis se realizó utilizando química en fase sólida y $N$ - $\delta$-alquilación directa e indirecta de los residuos peptídicos de ornitina. La actividad antimicrobiana se ensayó frente a cepas ATCC (American Type Culture Collection) mediante difusión en agar y determinación de la concentración inhibitoria mínima. El método directo de $N$-alquilación con carbonato de potasio fue el más adecuado con rendimientos del $40 \%$ permitiendo obtener compuestos mono y di alquilados biológicamente activos. La baja masa molecular de estos compuestos, su forma simple de obtención y su actividad hacia bacterias causantes de enfermedades de transmisión alimentaria los hace tecnológicamente atractivos para ser utilizados como preservadores alimentarios. La presencia de ornitina en las moléculas les otorga resistencia enzimática y vida media biológica mayor, por que podrían ser utilizados para el desarrollo de drogas con fines terapéuticos.

Palabras clave: péptido, gemini, actividad antimicrobiana, $N$ - $\delta$-alquilación, L-Ornitina.

\section{Synthesis and Biological Activity of New Peptide-Based Gemini Compounds}

\begin{abstract}
The antimicrobial activity of new gemini derived from a tetrapeptide has been evaluated. The synthesis was carried out using solid phase chemistry and $N$ - $\delta$-direct and indirect alkylation of the ornithine peptide residue. The antimicrobial activity was tested against ATCC strains (American Type Culture Collection) by well-diffusion assay and determination of minimal inhibitory concentration. The method of $\mathrm{N}$-alkylation with potassium carbonate was the best with yields of $40 \%$ allows achieving biologically active mono and dialkylate surfactants. The low molecular weight of these compounds, their simple way of preparation and their activity towards bacteria causing food-borne diseases makes them technologycally attractive for use as food preservatives. The presence in the molecules of ornithine gives them enzymatic resistance and a longer biological half-life and thus may be used to develop drugs for therapeutic purposes.
\end{abstract}

Keywords: peptide, gemini, antimicrobial activity, $N$ - $\delta$-alkylation, L-Ornithine. 


\section{INTRODUCCIÓN}

Los compuestos gemini son una clase relativamente nueva de moléculas anfipáticas que contienen dos cadenas apolares o hidrofóbicas y dos grupos polares o hidrofílicos unidos por un espaciador rígido o flexible (Menger y Keiper, 2000). Los grupos polares pueden presentar carga positiva (amonio) o negativa (fosfato, sulfato, carboxilato), mientras que los grupos polares no iónicos pueden ser poliéteres o azúcares (Hait y Moulik, 2002). Estos compuestos en general, actúan a nivel de la membrana celular de los microorganismos, causando la disrupción de la misma o la inhibición de enzimas que son esenciales para su desarrollo (Tewari et al, 2004). Por otro lado los compuestos gemini presentan en algunos casos, dependiendo de su estructura química, excelente biodegradabilidad y muy baja toxicidad (Menger y Mbadugha, 2001). Diferentes polioles, hidratos de carbono, alcoholes grasos, alquilglicósidos y aminas han sido usados, entre otros compuestos orgánicos, como materiales de partida para la construcción del grupo espaciador (Murguía et al., 2008).

Recientemente se han desarrollado gemini que contienen en su estructura componentes peptídicos y que han demostrado ser activos como agentes de transfección (Kirby et al., 2003) o antimicrobianos (Accardo et al., 2009). En la mayoría de estos trabajos utilizan para la hidrofobización del espaciador peptídico, el proceso sintético ampliamente conocido para la obtención de lipopéptidos, el cual consiste en conjugar mediante acilación una cadena peptídica con ácidos grasos de 12 a 18 carbonos de longitud (Jerala, 2007).

En el presente trabajo presentamos la síntesis, caracterización y actividad biológica de nuevos compuestos tipo gemini no iónicos (3a, 3b y 3c) (Fig. 1), diseñados a partir de un espaciador flexible derivado de un tetrapéptido $\left(P_{1}\right)$ hidrofobizado mediante $N$-alquilación de los grupos $\delta$ aminos de las cadenas laterales de ornitina con diferentes cadenas hidrofóbicas saturadas e insaturadas de 12 carbonos (Murguía et al., 2008).

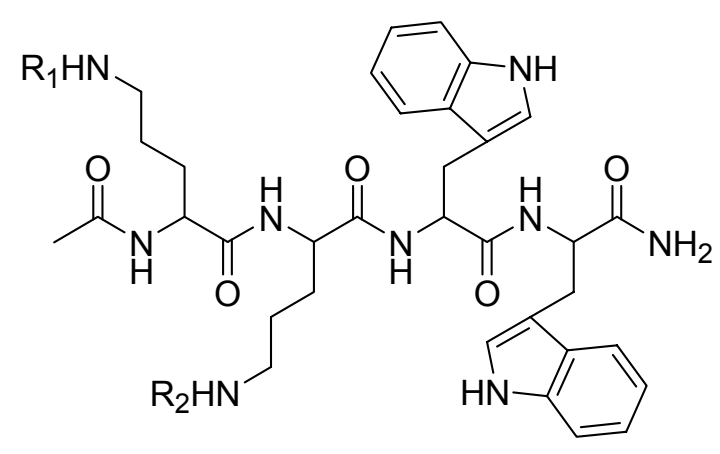

$$
\begin{aligned}
& 3 a, R_{1}=R_{2}=-C_{12} H_{24} ; 3 a-1, R_{1}=H, R_{2}=-C_{12} H_{24} \\
& 3 b, R_{1}=R_{2}=-C_{15} H_{25} ; 3 b-1, R_{1}=H, R_{2}=-C_{15} H_{25} \\
& 3 c, R_{1}=R_{2}=-C_{15} H_{30} O_{2} ; 3 c-1, R_{1}=H, R_{2}=-C_{15} H_{30} O_{2}
\end{aligned}
$$

Fig. 1: Compuestos sintetizados tipo gemini con cadenas saturadas (3a y $3 c$ ) e insaturadas (3b), y monoalquilados con cadenas saturadas (3a-1 y $3 c-1)$ e insaturadas (3b-1).

El espaciador peptídico fue sintetizado mediante química en fase sólida, empleando la estrategia del 9-fluorenilmetiloxicarbonilo (Fmoc) y funcionalizándose el extremo C-terminal como amida según la secuencia reportada por (Bisht et al., 2007). Dentro del diseño del espaciador peptídico, se han incorporado estrategias descriptas en la literatura, tales como acetilación del extremo $N$ terminal del péptido y la incorporación de aminoácidos no naturales como la ornitina, a fin de incrementar la actividad biológica y la vida media de los compuestos obtenidos (Adessi y Soto, 2002). Los métodos de $\mathrm{N}$-alquilación empleados están ampliamente descriptos en la literatura (Bowman et al., 1997; Salvatore et al., 2000; Srivastava et al., 1999). 
La capacidad de los diferentes compuestos sintetizados para inhibir el desarrollo de diferentes bacterias patógenas (estudios de actividad antimicrobiana) se estudió mediante el método de difusión en agar (Müller et al., 2007) y determinación de la Concentración Inhibitoria Mínima (CIM) (Amsterdam, 1996).

\section{MATERIALES Y MÉTODOS}

\section{Síntesis y purificación del espaciador peptídico}

El espaciador peptídico $\left(P_{1}\right)$ fue sintetizado mediante química en fase sólida (Merrifield, 1995), empleando la estrategia del 9-fluorenil-metoxicarbonilo (Fmoc) bajo la forma de péptido $C$-terminal carboxamida, y $\mathrm{N}$-terminal acetilo según la secuencia reportada en la bibliografía (Bisht et al., 2007): AcHN-Orn-Orn-Trp-Trp-CONH ${ }_{2}$. Como soporte sólido se utilizó una resina tipo Rink amida 4-metilbencidrilamina (Sigma) y la síntesis se realizó en forma manual. Los Fmoc aminoácidos (Sigma) se acoplaron al soporte sólido utilizando hexafluorofosfato de $1 \mathrm{H}$-benzotriazol-1-iloxi-tris (pirrolidino) fosfonio (PyBOP) en presencia de $\mathrm{N}$-metilmorfolina como catalizador. El grupo Fmoc fue eliminado en las etapas de desprotección empleando piperidina al $20 \%$ en N,Ndimetilformamida (DMF). Los solventes usados fueron de calidad grado HPLC. El monitoreo de las reacciones se realizó por los métodos convencionales para este tipo de síntesis (Merrifield, 1995). El péptido fue desprotegido y simultáneamente separado de la resina en un único paso empleando una mezcla de ácido trifluoracético/agua/triisopropilsilano (TFA/ $\left.\mathrm{H}_{2} \mathrm{O} / \mathrm{TIS}\right)(90: 5: 5)(\mathrm{v} / \mathrm{v})$. El producto de síntesis fue separado de la mezcla de reacción por precipitación con éter etílico a $4^{\circ} \mathrm{C}$, centrifugación y liofilización.

El espaciador peptídico fue purificado usando una columna Sep-Pak C18 (Supelco) equilibrada con dos sistemas solventes: (A) metanol y (B) agua Mili $Q$. Las muestras en estudio fueron filtradas a través de filtros de $0.45 \mu \mathrm{m}$ (Minisart RC 4, Sartorius) y disueltas en agua Mili Q. La elusión se realizó aplicando un gradiente de $0-100 \% A(\mathrm{v} / \mathrm{v})$, velocidad de flujo $2 \mathrm{~mL} / \mathrm{min}$. Las muestras recolectadas fueron analizadas por cromatografía en capa delgada (CCD) y espectrometría de masas de alta resolución (EM). Las fracciones eluidas correspondientes al péptido puro fueron concentradas y posteriormente liofilizadas y conservadas $a-18^{\circ} \mathrm{C}$.

\section{Síntesis y purificación de los compuestos gemini no iónicos}

La síntesis de los compuestos gemini no iónicos con cadenas saturadas (geminis 3a y 3c) se realizó mediante dos tipos de $\mathrm{N}$-alquilaciones directa e indirecta respectivamente.

$\mathrm{N}$-alquilación directa (Fig. 2): se estudiaron dos sistemas reactivos para la obtención del gemini 3a: a) con una relación molar de reactivos de 1:2.7:2, $\mathrm{P}_{1}(0.03 \mathrm{~g}, 0.04 \mathrm{mmol})$, bromuro de docecilo (Sigma-Aldrich) $(0.02 \mathrm{~g}, 0.1 \mathrm{mmol})$, carbonato de potasio (Sigma-Aldrich) $(0.01 \mathrm{~g}, 0.06 \mathrm{mmol}$ ), (Salvatore et al., 2000; Srivastava et al., 1999); y b) con una relación molar de reactivos de $1: 2.7: 2: 0.1, \mathrm{P}_{1}(0.03 \mathrm{~g}, 0.04 \mathrm{mmol})$, bromuro de docecilo $(0.02 \mathrm{~g}, 0.1 \mathrm{mmol})$, trietilamina (SigmaAldrich) $(0.006 \mathrm{~g}, 0.06 \mathrm{mmol})$, bromuro de tetrabutilamonio (BrTBA) como catalizador (SigmaAldrich), (0.09g, $0.3 \mathrm{mmol}$ ), (Bowman et al., 1997). En ambos sistemas (a y b) se uso DMF como sistema solvente y se agitó vigorosamente a temperatura ambiente $\left(25^{\circ} \mathrm{C}\right)$. Luego de completada la reacción (desaparición de $\mathrm{P}_{1}$ mediante $C C D$ ), la mezcla reactiva fue liofilizada y conservada a $18^{\circ} \mathrm{C}$ hasta su purificación.

$N$-alquilación indirecta (Fig.3): En primer lugar se sintetizó el éter monoglicidílico derivado del dodecanol (EMG) mediante catálisis por transferencia de fase según técnica reportada en la literatura (Murguía et al., 2008) y su estructura fue confirmada mediante Resonancia Magnética Nuclear (RMN) de ${ }^{1} \mathrm{H}$. Posteriormente se realizó la $\mathrm{N}$-alquilación del $\mathrm{P}_{1}$ con el EMG en presencia de BrTBA y carbonato de potasio, obteniéndose el gemini $3 \mathrm{c}$ con la siguiente relación molar: $1: 2: 2: 0.1, P_{1}(0.03 \mathrm{~g}, 0.04 \mathrm{mmol})$, EMG $(0.01 \mathrm{~g}, 0.06 \mathrm{mmol})$, carbonato de potasio $(0.006 \mathrm{~g}, 0.06$ $\mathrm{mmol}$ ), BrTBA (catalizador) (Sigma-Aldrich), (0.09g, $0.3 \mathrm{mmol}$ ), en DMF a $25^{\circ} \mathrm{C}$. 
<smiles>[R][CH-][C@H](NC(C)=O)C(=O)N[C@@H](CCCN)C(=O)N[C@@H](Cc1c[nH]c2ccccc12)C(=O)N[C@@H](Cc1c[nH]c2ccccc12)C(N)=O</smiles>

$P_{1}$<smiles>[R17]NCCC[C@H](NC(C)=O)C(=O)N[C@@H](CCCN[R2])C(=O)N[C@@H](Cc1c[nH]c2ccccc12)C(=O)N[C@@H](Cc1c[nH]c2ccccc12)C(N)=O</smiles>

3a, $\mathrm{R}_{1}=\mathrm{R}_{2}=-\mathrm{C}_{12} \mathrm{H}_{24} ; 3 \mathrm{a}-1, \mathrm{R}_{1}=\mathrm{H}, \mathrm{R}_{2}=-\mathrm{C}_{12} \mathrm{H}_{24}$ $3 b, R_{1}=R_{2}=-C_{15} H_{25} ; 3 b-1, R_{1}=H, R_{2}=-C_{15} H_{25}$

Fig. 2: $N$ - $\delta$-alquilación directa, Reactivos y condiciones: (i) Sistema a: carbonato de potasio, DMF, $25^{\circ} \mathrm{C}, 48 \mathrm{~h}$ (ii) Sistema b: trietilamina, BrTBA, DMF, $25^{\circ} \mathrm{C}, 120 \mathrm{~h}$.<smiles>[R20]CC(O)CNCCCC(NC(C)=O)C(=O)NC(CCCNCC(O)C[R20])C(=O)NC(Cc1c[nH]c2ccccc12)C(=O)NC(Cc1c[nH]c2ccccc12)C(N)=O</smiles>

3c, $\mathrm{R}_{1}=\mathrm{R}_{2}=-\mathrm{C}_{15} \mathrm{H}_{30} \mathrm{O}_{2}$

$3 \mathrm{c}-1, \mathrm{R}_{1}=\mathrm{H}, \mathrm{R}_{2}=-\mathrm{C}_{15} \mathrm{H}_{30} \mathrm{O}_{2}$

Fig. 3: $N$ - $\delta$-alquilación indirecta, Reactivos y condiciones: ( \pm ) (i) epiclorhidrina, $\mathrm{NaOH}$ aq, $\mathrm{BrTBA}$, hexano, $30^{\circ} \mathrm{C}, 5 \mathrm{~h}$; (ii) $\mathrm{P}_{1}$, BrTBA, carbonato de potasio, DMF, $25^{\circ} \mathrm{C}, 48 \mathrm{~h}$.

La síntesis de los compuestos gemini no iónicos con cadenas insaturadas (gemini $3 b$ ) se realizó mediante el método de $\mathrm{N}$-alquilación directo "sistema a", mediante el uso de bromuro de trans, trans-farnesilo (Sigma-Aldrich).

Todas las reacciones se llevaron a cabo en atmósfera de nitrógeno y fueron monitoreadas mediante CCD sobre placas de sílica gel con indicador fluorescente $254 \mathrm{~nm}$ de $0.2 \mathrm{~mm}$ (Fluka), empleando como sistemas reveladores: luz UV, yodo, $p$-anisaldehído y ninhidrina. Todos los disolventes usados fueron de calidad grado HPLC o destilados antes de ser usados.

Los diferentes gemini obtenidos tanto por alquilación directa como indirecta fueron purificados usando columnas Sep-Pak C4 (Supelco). Las columnas fueron equilibradas con dos sistemas solventes: $(A)$ metanol y (B) agua Mili $Q$. Las muestras en estudio fueron filtradas a través de filtros de $0.45 \mu \mathrm{m}$ (Minisart RC 4, Sartorius) y disueltas en DMF. La elusión se realizó aplicando un gradiente de 0-100 A \% (v/v). Las muestras recolectadas fueron analizadas mediante CCD y EM. Las fracciones eluidas que contenían a los gemini puros fueron concentradas posteriormente liofilizadas y conservadas a $-18^{\circ} \mathrm{C}$. Finalmente se realizó el cálculo de los rendimientos postpurificación de los diferentes compuestos obtenidos.

\section{Métodos analíticos empleados}

El espectro de resonancia magnética nuclear (RMN) de ${ }^{1} \mathrm{H}$, fue obtenido en un equipo Bruker 300 $\mathrm{MHz}$ de Advance Spectrometers. Los desplazamientos químicos $(\delta)$ son expresados en ppm. Para 
describir la presencia de multipletes, singuletes, dobletes, tripletes y cuadrupletes se utilizan las letras $\mathrm{m}, \mathrm{s}, \mathrm{d}, \mathrm{t}, \mathrm{y} \mathrm{q}$. Los análisis de espectrometría de masas de alta resolución (EM) se realizaron en un equipo VGmAutospec (VG Analytical, Micromass Instruments) a través del servicio de espectrometría de masas de la Universidad de Valencia (España).

\section{Ensayos de actividad antimicrobiana}

Para todos los compuestos sintetizados se utilizaron como indicadores de la actividad antimicrobiana las siguientes cepas bacterianas pertenecientes a la American Type Culture Collection (ATCC): Bacillus subtilis ATCC 6633; Staphylococcus aureus ATCC 25923; Escherichia coli ATCC 25922 y Pseudomonas aeruginosa ATCC 27857.

La actividad antimicrobiana fue evaluada mediante el ensayo de difusión en agar (Müller et al., 2007), para lo cual se agregó $1 \mathrm{~mL}$ del cultivo de 12-16 h de cada cepa indicadora usada sobre 19 $\mathrm{mL}$ de Agar Mueller Hinton (Britania) y se colocó en una placa de Petri estéril. Luego de enfriar a temperatura ambiente, se realizaron pozos de $5 \mathrm{~mm}$ de diámetro en las placas, y se colocaron $35-$ $50 \mu \mathrm{L}$ de solución en dimetilsulfóxido (DMSO) de los compuestos a una concentración de $1 \mathrm{mg} / \mathrm{mL}$. Las placas se incubaron a $37^{\circ} \mathrm{C}$ durante $24 \mathrm{~h}$ y luego se midieron los diámetros correspondientes a los halos de inhibición. Cada ensayo fue realizado por duplicado, y los resultados se expresaron como el promedio de los valores medidos.

Las determinaciones de CIM fueron realizadas usando el método de dilución en caldo modificado para péptidos antimicrobianos catiónicos. Se ajustó la concentración celular de los cultivos de las cepas indicadoras utilizadas a un valor de $5.10^{7} \mathrm{UFC} / \mathrm{mL}$, y alícuotas de los cultivos estandarizados se diluyeron con caldo Mueller-Hilton (Britania) al $10 \%$ (Zelezetsky et, al. 2005).

Se prepararon soluciones stock de los diferentes compuestos ensayados en DMSO, todos los test incluyeron controles (Blancos) de reactivos y de cepas bacterianas indicadoras. Cada ensayo fue realizado por duplicado y los resultados se expresaron como el promedio de los valores medidos.

Se consideró como CIM la concentración de compuesto que redujo el $100 \%$ de crecimiento de la cepa bacteriana ensayada en comparación con el cultivo control $\left(\mathrm{CIM}_{100}\right)$.

\section{RESULTADOS Y DISCUSIÓN}

El rendimiento de la síntesis del espaciador peptídico $\left(P_{1}\right)(P . M o l .659 .29)$ fue del orden del $70 \%$, obteniéndose $95 \mathrm{mg}$ de péptido crudo (AcHN-Orn-Orn-Trp-Trp-CONH${ }_{2}$ ) a partir de $200 \mathrm{mg}$ de resina, escala de síntesis $0.22 \mathrm{mmol}$. Luego de la purificación mediante columnas de C18 se obtuvo un único pico con pureza mayor al $95 \%$. Espectro de masas [m/z, intensidad relativa]: $660,36\left[(\mathrm{M}+\mathrm{H})^{+}, 100\right]$.

La síntesis de los compuestos gemini no iónicos con cadenas saturadas e insaturadas (geminis $3 a$ y 3 b respectivamente) se realizó mediante $N$-alquilación directa, estudiándose además la $N$ alquilación indirecta mediante el uso de cadenas saturadas (gemini 3c). Mediante $N$-alquilación directa (Fig. 2) se estudiaron dos sistemas reactivos para la obtención del gemini 3a, el sistema reactivo a (carbonato de potasio y bromuro de dodecilo, $\mathrm{pH} 8$ ) y el sistema reactivo $\mathrm{b}$ (trietilamina, bromuro de tetrabutilamonio como catalizador y bromuro de dodecilo, $\mathrm{pH} 6$ ). En el sistema con carbonato se obtuvo $40 \%$ de rendimiento de gemini 3a (P.Mol. 996.58) y $19 \%$ de producto mono alquilado (3a-1) (P.Mol. 827.58), observándose polialquilación (producto hidrofobizado con tres cadenas (P.Mol 1163.93) solo en el sistema con carbonato de potasio. Espectro de masas sistema a [m/z, intensidad relativa]: $996.74\left[(\mathrm{M})^{+} 3 \mathrm{a}, 43\right] ; 856.54\left[(\mathrm{M}+6 \mathrm{H})^{+} 3 \mathrm{a}-1,55\right] ; 1164.93\left[(\mathrm{M}+\mathrm{H})^{+}\right.$ producto poli alquilado, 19] y $663.53\left[(\mathrm{M}+3 \mathrm{H})^{+} \mathrm{P}_{1}, 65\right]$. En el sistema con trietilamina, los rendimientos de producto $3 a$ fueron considerablemente menores a los obtenidos con carbonato, detectándose importante alquilación de la trietilamina. Espectro de masas sistema b [m/z, intensidad relativa]: $270.3184\left[(\mathrm{M})^{+}\right.$trietilamina mono alquilada, 45]; $498.88\left[(\mathrm{M} / 2)^{+} 3 \mathrm{a}, 10\right]$; $996.75\left[(\mathrm{M})^{+} 3 \mathrm{a}, 25\right]$. 
No se observaron mejoramientos en los rendimientos a $\mathrm{pH}$ de reacción mayores a 8 , empleando etanol como sistema solvente o mediante el agregado de un exceso de bromuro de docecilo mayor a $2.7 \mathrm{mmol}$ por cada $\mathrm{mmol}$ de $\mathrm{P}_{1}$. Los tiempos de reacción fueron de $48 \mathrm{~h}$ para el sistema con carbonato y $120 \mathrm{~h}$ para el sistema con trietilamina.

La $\mathrm{N}$-alquilacion de los grupos amino de las cadenas laterales de las ornitinas resultó dependiente del $\mathrm{pH}$, siendo mas eficiente a $\mathrm{pH} 8$ en el "sistema a". Esto ocurre debido a que generalmente en los péptidos de bajo peso molecular los grupos amino ionizables de las cadenas laterales de los aminoácidos, mantienen los pK muy cerca de los valores del aminoácido libre y teniendo en cuenta que el pK de los residuos de ornitina es aproximadamente 10.6, cuanto mayor sea el pH, mas nucleofílicos serán estos grupos para reaccionar con el halogenuro de alquilo correspondiente.

El método de alquilación mediante el empleo de carbonato resultó ser mas adecuado por diferentes razones, es un método mas sencillo (no requiere catalizador), requiere menor tiempo de reacción y los rendimientos son mayores respecto al sistema mediante el empleo de trietilamina.

Mediante $\mathrm{N}$-alquilacion indirecta (Fig. 3), se obtuvo en primer lugar el EMG $\left(\mathrm{C}_{15} \mathrm{H}_{30} \mathrm{O}_{2}: \mathrm{P} . \mathrm{Mol}\right.$ 243.398) con un rendimiento del $63 \%$ cuya estructura fue confirmada por RMN: ${ }^{1} \mathrm{H}$ NMR [300 $\mathrm{MHz},(\mathrm{CDCl} 3)]$ con los siguientes desplazamientos $(\delta)=0.82(\mathrm{t}, 3 \mathrm{H}), 1.24-1.27(\mathrm{~m}, 18 \mathrm{H}), 1.51(\mathrm{t}$, $2 \mathrm{H}), 2.53-2.75(\mathrm{~m}, 2 \mathrm{H}), 3.06-3.11(\mathrm{~m}, 1 \mathrm{H}), 3.3-3.49(\mathrm{~m}, 2 \mathrm{H}), 3.61-3.66(\mathrm{~m}, 2 \mathrm{H})$.

Luego la $N$-alquilación del péptido $\mathrm{P}_{1}$ con el EMG produjo un $62 \%$ de gemini 3c (P.mol. 1143.29), y $38 \%$ de producto mono alquilado (3c-1) (P.Mol. 901.29) (Fig. 1), la reacción se completó en 96 horas a $\mathrm{pH}$ 8. Espectro de masas [m/z, intensidad relativa]: $1144.81\left[(\mathrm{M}+\mathrm{H})^{+} 3 \mathrm{c}, 12\right] ; 940.54$ $\left[(\mathrm{M}+\mathrm{K})^{+} 3 \mathrm{c}-1,43\right]$.

Si bien el método indirecto presentó los rendimientos mas altos de producto deseado (gemini), es un método que presenta mayor cantidad de pasos sintéticos y purificaciones con condiciones de reacción mas fuertes $\left(40^{\circ} \mathrm{C}\right)$, mas contaminantes (presencia de epiclorhidrina) y tiempos de reacción largos. Por todo esto, la síntesis del compuesto gemini no iónico con cadenas insaturadas se realizó mediante el método de $N$-alquilacion directa "sistema a", obteniéndose el gemini 3b (P.Mol. 1068.05) con un rendimiento de $38 \%$ y $52 \%$ de producto monoalquilado (3b-1) (P.Mol. 863.7) (Fig. 1) sin poli-alquilación. Espectro de masas [m/z, intensidad relativa]: 550.35 $\left.\left[(\mathrm{M} / 2)^{+} 3 \mathrm{~b}, 10\right] ; 454.43[(\mathrm{M}+3 \mathrm{H}) / 2]^{+} 3 \mathrm{~b}-1,100\right]$.

En los últimos años, se han descripto una gran cantidad de métodos de $N$-alquilación: métodos reductivos (Carter, 1994), métodos que emplean grupos protectores (Ojima, 1993), métodos directos (Salvatore et al., 1999) y métodos que utilizan sales de cesio (Salvatore et al., 2000) salvo este último, todos ellos pueden transcurrir con poli alquilaciones (formación de aminas terciarias y sales de amonio cuaternarias) y además el uso de grupos protectores requiere secuencias sintéticas largas y el uso de reactivos tóxicos y caros. Si bien la polialquilación en el método directo puede evitarse mediante el uso de un exceso de amina, esta es una alternativa muy costosa.

Existen muy pocos trabajos donde se realice la $N$-alquilación de residuos aminoacídicos, por ejemplo el grupo de Lundquist y col., 1999 ha sintetizado análogos del extremo $C$-terminal del neuropéptido neurotensina, conteniendo análogos $N$ - $\varphi$-alquilados de Orn, Lys, Hys, que le otorgan resistencia enzimática y mayor capacidad para atravesar los tejidos cerebrales. Nuestro trabajo es el primero reportado en la literatura sobre hidrofobización de péptidos mediante la $N-\delta$-alquilación de cadenas laterales de ornitinas.

Nuestro objetivo ha sido realizar la síntesis del estos compuestos anfifilicos empleando un medio simple de reacción, con reactivos accesibles a cualquier laboratorio (carbonato de potasio), en un medio disolvente aprótico (DMF) para aumentar la quimioselectividad de la reacción (Salvatore et al., 2000) y sin necesidad de utilizar grupos protectores (ya que el péptido se encuentra preacetilado en su extremo $N$-terminal) o un exceso de amina (en este caso $\mathrm{P}_{1}$ ) para evitar poli- 
alquilaciones debido a que los agentes alquilantes utilizados presentan cadenas de mas de 5 carbonos de longitud, lo cual favorece considerablemente la mono alquilación de cada residuo de ornitina (Salvatore et al., 2001).

En la Tabla 1 se observa el espectro inhibitorio de los diferentes compuestos sintetizados: péptido $\mathrm{P}_{1}$, compuestos peptídicos gemini y productos monoalquilados respectivos. Los ensayos de actividad antimicrobiana se debieron realizar disolviendo los diferentes gemini y compuestos mono alquilados en solución al $100 \%$ de DMSO, debido a que los mismos fueron insolubles en agua.

(Bisht et al., 2007) han encontrado que el $P_{1}$ presentó actividad inhibitoria hacia diferentes bacterias patógenas: P. Aeruginosa (MTCCB, 741), CIM 256; E. coli (MTCCB, 1610), CIM 512; S. aureus (MTCCB, 96), CIM 128; B. subtilis (NCIM, 2063), CIM 512; E. coli (aislado clínico) con valores de $\mathrm{CIM}_{80}$ de 741, 256, 512, 128 y 512 respectivamente. En cambio mientras que el mismo péptido $P_{1}$ sintetizado en nuestro laboratorio no presentó actividad inhibitoria hacia ninguna de las cepas de colección ensayadas, los compuestos gemini y mono alquilados obtenidos del $P_{1}$ si presentaron actividad.

Tabla 1. Espectro antimicrobiano de los compuestos sintetizados. El diámetro de los pozos (5 mm) no fue sustraído del halo de inhibición observado en cada caso; (-) Ausencia de halo de inhibición.

\begin{tabular}{|c|c|c|c|c|c|c|c|}
\hline \multirow[b]{2}{*}{ Cepas indicadoras } & \multicolumn{7}{|c|}{ Compuestos } \\
\hline & $\mathrm{P}_{1}$ & $3 a-1$ & $3 a$ & $3 b-1$ & $3 b$ & $3 c-1$ & $3 c$ \\
\hline B. subtilis ATCC 6633 & - & 12 & 8 & 18 & - & 7 & - \\
\hline S. aureus ATCC 25923 & - & 11 & 7 & 15 & 6 & 6.8 & - \\
\hline E. coli ATCC 25922 & - & 8 & - & 13 & - & 6.5 & - \\
\hline$P$. aeruginosa ATCC 27857 & - & 8 & - & 7 & 7 & 6.5 & 7 \\
\hline
\end{tabular}

Los compuestos mono alquilados con cadenas saturadas e insaturadas 3a-1, 3c-1 y $3 b-1$ presentaron mayor espectro inhibitorio que los respectivos gemini no iónicos (3a, 3c y $3 b)$. Si bien la presencia de carga es importante en la interacción inicial de la mayoría de los péptidos antimicrobianos con la membrana de las células bacterianas (Müller et al., 2007), la actividad biológica de este tipo de compuestos anfif́licos depende de un adecuado balance carga/hidrofobicidad en sus estructuras. A pH menor a 10 (rango de los ensayos biológicos), tanto los compuestos mono alquilados como los gemini pueden presentan carga +2 , pero la relación carga/hidrofobicidad es menor para los gémini que para los monoalquilados. Es posible que la presencia de dos residuos de triptofano sumada a las dos cadenas hidrofóbicas de 12 carbonos haga que los compuestos gemini tengan un espectro de inhibición mas reducido.

De los compuestos peptídicos mono alquilados obtenidos por el método directo, el $3 b-1$ fue el de mayor espectro inhibitorio y menores valores de $\mathrm{CIM}_{100}$, fundamentalmente frente a bacterias causantes de enfermedades de transmisión alimentaria (ETA) como Escherichia coli 0 Staphylococcus aureus (Anselmo et al., 2010) (Tabla 2). Los valores de $\mathrm{CIM}_{100}$ hallados para el compuesto 3b-1 son considerablemente menores a los hallados por (Bisht et al., 2007), para el péptido sin hidrofobizar (Tabla 2).

Tabla 2. Concentración Inhibitoria mínima de los compuestos sintetizados.

ND: No Determinado.

\begin{tabular}{|c|c|c|c|c|c|c|c|}
\hline \multirow{2}{*}{ Cepas indicadoras } & \multicolumn{7}{|c|}{ Compuestos } \\
\cline { 2 - 8 } & $\mathrm{P}_{1}$ & $3 a-1$ & $3 a$ & $3 b-1$ & $3 b$ & $3 c-1$ & $3 c$ \\
\hline B. subtilis ATCC 6633 & ND & $>1265$ & 94.8 & 40 & ND & ND & ND \\
\hline S. aureus ATCC 25923 & ND & $>1265$ & 189.6 & 320 & 908 & ND & ND \\
\hline E. coli ATCC 25922 & ND & 1265 & ND & 62.5 & ND & ND & ND \\
\hline P. aeruginosa ATCC 27857 & ND & $>1265$ & ND & 62.5 & $>908$ & ND & ND \\
\hline
\end{tabular}


De los tres compuestos gemini sintetizados el 3a fue el mas activo ya que presentó menores valores de $\mathrm{CIM}_{100}$ fundamentalmente frente a Staphylococcus aureus ATCC 25923 (Tabla 1). El producto poli alquilado con tres cadenas saturadas resultó inactivo frente a todas las cepas ensayadas.

\section{CONCLUSIONES}

Los resultados obtenidos indican que la $\mathrm{N}$ - $\delta$-alquilación directa de los residuos de ornitina del péptido $P_{1}$ mediante el método directo con carbonato de potasio permite obtener de una forma sencilla y rápida compuestos anfifilos peptídicos con rendimientos aceptables.

La hidrofobización realizada por nuestro grupo de trabajo sobre el péptido reportado por (Bisht et al., 2007) aumentó considerablemente su espectro antimicrobiano de acción tanto sobre bacterias Gram (+) como Gram (-), causantes de enfermedades patógenas del ser humano como Pseudomonas aeruginosa o causantes de ETA como Bacillus subtilis, Escherichia coli o Staphylococcus aureus.

Todos estos compuestos pero especialmente los anfifilos peptídicos de mayor actividad obtenidos (3a y 3b-1), presentan bajos pesos moleculares y pueden ser obtenidos por un método simple de $\mathrm{N}$-alquilacion, esto los torna atractivos tecnológicamente para ser producidos en mayor escala. De igual manera, la presencia en la molécula de análogos $N$ - $\delta$-alquilados de ornitina (aminoácido no natural) los hace resistentes a la acción de numerosas enzimas como aminopeptidasas, aumentando la vida media del compuesto, lo cual es un hecho importante en el desarrollo de nuevas drogas con fines terapéuticos. Debido a esto, nuestro trabajo continúa actualmente con la evaluación de la actividad hemolítica de los compuestos sintetizados y la obtención de las correspondientes sales de bis-amonio cuaternarias (QACs) o geminis catiónicos a partir de los geminis no iónicos obtenidos ( $3 a$ y $3 b$ ) a fin de mejorar su actividad biológica ya que esto permitiría mejorar la relación carga/hidrofobicidad de dichas moléculas facilitando el proceso de disrupción celular de las células blanco, aumentando por consiguiente su actividad antimicrobiana.

\section{AGRADECIMIENTOS}

Este trabajo fue realizado en el marco del Proyecto CAI+D 2009 de la Universidad Nacional del Litoral, Santa Fe, República Argentina, agradecemos al Dr. D. Santos Fustero Lardiés de la Universidad de Valencia, España, por la realización de los EM y de RMN.

\section{REFERENCIAS}

Accardo, A. y otros ocho autores, Micelles obtained by aggregation of gemini surfactants containing the CCK8 peptide and a gadolinium complex, J. Biol. Inorg. Chem. :14, 587-599 (2009).

Adessi, C. y Soto, C; Converting a peptide into a drug: strategies to improve stability and bioavailability, Curr. Med. Chem.: 9, 963-978 (2002).

Anselmo, R. J., Viora, Silvia S., Ojeda, P.A y Lausada, L I., Efecto Antagónico del Kefir sobre Endosporas y Células Vegetativas de Bacillus Cereus y Clostridium Perfringens. Inf. tecnol. [online], 21(4), 131-138 (2010).

Bisht, G.S. y otros cuatro autores; Antimicrobial activity of rationally designed amino terminal modified peptides, Bioorg. Med. Chem. Lett: 17, 4343-4346 (2007).

Bowman, W.R. y D.R. Coghlan; A Facile Method for the N-Alkylation of a-Amino Esters Tetrahedron: 53 (46), 15787-15798 (1997).

Carter, C., For a comprehensive review on the neuropharmacology of polyamines, ver: The Neuropharmacology of Polyamines; Ed.; Academic Press: San Diego (1994). 
Hait, S. K. y S. P. Moulik; Gemini surfactants: A distinct class of self-assembling molecules Current Science: 82 (9), 1101-1111 (2002).

Jerala, R; Synthetic lipopeptides: a novel class of anti-infectives, Expert. Opin. Investig. Drugs.: 16(8),1159-69. (2007)

Kirby, A. J. y otros quince autores; Gemini Surfactants: New Synthetic Vectors for Gene Transfection, Angew. Chem. Int. Ed.: 42, 1448-1457 (2003).

Lundquist IV, J. T. y T. A. Dix; Synthesis of ö-Bromo-2-(S)-Azido Acids as Precursors for the Synthesis of Novel Amino Acids. Tetrahedron Lett: 39, 775-778 (1998).

Menger, F. M. y J. S. Keiper, Gemini surfactans, Angew. Chem. Int. Ed.: 39, 1906-1920 (2000).

Menger, F.M. y B.N.A. Mbadugha; Gemini surfactants with a disaccharide spacer, J. Am. Chem. Soc: $123,875-885$ (2001).

Merrifield, R.B., Solid- phase peptide synthesis- In Peptides: Synthesis, Structures, and Applications, Academic Press (San Diego, USA): 93-169 (1995).

Müller, D.M, y otros cuatro autores; A synthetic analog of plantaricin 149 inhibiting food-borne pathogenic bacteria:evidence for $\alpha$-helical conformation involved in bacteria-membrane interaction, J. Pept. Sci: 13 (3), 171-178 (2007).

Murguía, M. C., y otros cuatro autores; Synthesis and Properties of Novel Antifungal Gemini Compounds Derived from N-Acetyl Diethanolamines, Surfact Deterg 11, 223-230 (2008).

Ojima, I., Catalytic Asymmetric Synthesis, VCH Verlag: Weinheim, (1993).

Salvatore, R.N. y otros cinco autores, $\mathrm{CsOH}$-promoted chemoselective mono-N-alkylation of diamines and polyamines, Tetrahedron Letters: 41, 9705-9708 (2000).

Salvatore, R.N., A. S. Nagle, S. E. Schmidt, K. W. Jung, Cesium Hydroxide Promoted Chemoselective N-Alkylation for the Generally Efficient Synthesis of Secondary Amines, Org. Lett: 1, 1893-1896 (1999).

Salvatore, R.N., C.H. Yoon, K.W. Jung, Synthesis of secondary amines. Tetrahedron: 57, 77857811 (2001).

Srivastava, S.K., P.M.S. Chauhan, A.P. Bhaduri; A novel strategy for N-alkylation of primary amines, Synth. Commun: 29, 2085-2091 (1999).

Tewari N, y otros 10 autores Synthesis of galactopyranosyl amino alcohols as new class of antitubercular and antifungal agents. Bioorg. Med. Chem. Lett: 14, 329-332 (2004).

Zelezetsky, I., y otros seis autores, Controlled alteration of the shape and conformational stability of alphahelicalcell-lytic peptides: effect on mode of action and cell specificity. Biochem. J: 390, 177-188 (2005). 
